\author{
EVS26 \\ Los Angeles, California, May 6-9, 2012
}

\title{
Electric wheel hub motor with high recuperative brake performance in automotive design
}

\author{
Dr.-Ing. Gunter Freitag ${ }^{1}$, Dr.-Ing. Marco Schramm ${ }^{2}$ \\ ${ }^{1}$ Siemens AG, Otto-Hahn-Ring 6, 81739 München, gunter.Freitag@siemens.com \\ ${ }^{2}$ Siemens AG, Günther-Scharowsky-Str. 1, 91050 Erlangen, schramm.marco@siemens.com
}

\begin{abstract}
The entire drive integration in the wheels of electric cars enables completely new vehicle drive train concepts and liberties with the interior design. Central motor, external gearing, differentials, axels and drive-shafts are no longer required, which leads to an enormous gaining of free space for the passenger compartment or other car components. Fully new car concepts and designs will become feasible. As well it can help to reduce weight and costs and increases the efficiency of the whole drive system. In addition wearout and maintenance expenditure are reduced to a minimum. Decentralized electric drives also enable new functionalities mainly concerning vehicle dynamics. This aspect counts especially for wheel hub motors because of the direct access to the wheels without any component in between. Another significant advantage is that direct drives in general are not prone to oscillations during load changes comparing to central drives with transmission gear, coupling and drive-shaft. In this article a review on the development of a wheel hub motor is given that is designed to substitute the friction brake on the rear axle. This demand special thought towards a system that accelerates and decelerates. High torque and power densities are achieved. Furthermore it is designed to be use in typical automotive conditions and vicinities. Indisputable a wheel hub motor adds more weight to the rim. Hence the impact of the increase of the unsprung masses is discussed in this article.
\end{abstract}

Keywords: wheel hub motor, regenerative braking, traction control, synchronous motor

\section{Introduction}

The entire drive integration in the wheels of electric cars enables completely new vehicle drive train concepts and liberties with the interior design. Central motor, external gearing, differentials, axels and drive-shafts are no longer required, which leads to an enormous gaining of free space for the passenger compartment or other car components. Fully new car concepts and designs will become feasible. As well it can help to reduce weight and costs and increases the efficiency of the whole drive system. In addition wearout and maintenance expenditure are reduced to a minimum. Decentralized electric drives also enable new functionalities mainly concerning vehicle dynamics, like torque vectoring and electrodynamic realization forms of known advanced driver assistance systems i.e. antilock braking system (ABS), electronic stability system (ESP) or traction control system (TCS). This aspect counts especially for wheel hub motors because of the direct access to the wheels without 
any component in between. Another significant advantage is that direct drives in general are not prone to oscillations during load changes comparing to axle drives with transmission gear, coupling and drive-shaft. Based on the lack of gear trains and additional shafts the direct drive is very rigid with a low backlash.

\section{Development Goals}

The main target of the research activities described in this article is the development of an electric wheel hub motor with highest torque and power density, to fit into a wheel and generate enough torque and power for the specific application at the same time. Furthermore the machine is designed to completely replace the friction brake system on the rear axis of a vehicle. It was planed from the very beginning to integrate and test two wheel hub motors in a prototype vehicle for urban applications. Torque vectoring and electrodynamic driver assistance systems, e.g. ABS, ESP and TCS, shall be realized with the available hardware and software architecture. A further important development priority is an automotive compatible design, i.e. IP67 and a maintenance-free sealing and bearing concept, considering to the special environmental conditions outside the car body. Also an easy integration into the vehicle shall be enabled.

\section{Electric machine design}

To reach the very high power and torque density we decided to design the active part of the wheel hub drive as a permanent magnetic synchronous machine (PSM). By this means we meet the requirements for torque and speed as defined by the vehicle specification regarding to acceleration and breaking with a machine housing that totally fits into a common 19" rim. Figure 1 shows the housing design of the wheel hub motor, the overall machine mass without cooling liquid is $50 \mathrm{~kg}$.

The torque-speed characteristic curves are shown in Figure 2. One motor has a continuous torque of $500 \mathrm{Nm}$ from zero to $1200 \mathrm{rpm}$, which is equivalent to ca. $140 \mathrm{~km} / \mathrm{h}$. A peak torque of 1250 $\mathrm{Nm}$ for a short term of $20 \mathrm{~s}$ will be achieved up to $840 \mathrm{rpm}$ (ca. $100 \mathrm{~km} / \mathrm{h}$ ) with a maximum current of $260 \mathrm{~A}_{\mathrm{rms}}$. The continuous power is up to $73 \mathrm{~kW}$ at maximum speed of $180 \mathrm{~km} / \mathrm{h}$, the maximum power is about $120 \mathrm{~kW}$ above $1200 \mathrm{rpm}$ to maximum speed.

Considering the extremely harsh environmental conditions we use an inner rotor design with a sealing diameter which is as small as possible. Therefore the speed between moving parts could be reduced to a minimum. This makes it clearly easier to reach for a high protection class over the whole lifetime. For the mechanical interface between the car body and the wheels we used the standard wheel hub components to ensure a robust and easy integration.

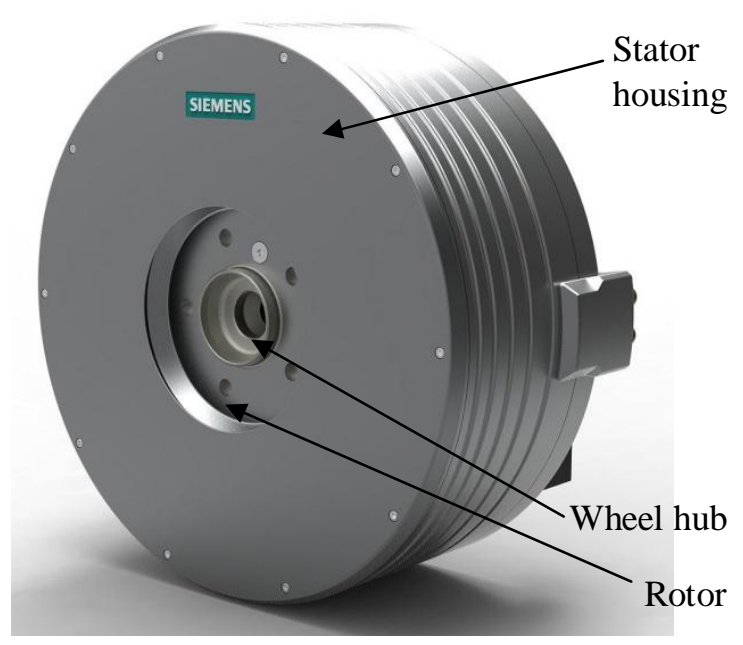

Figure 1: Siemens electric wheel hub motor

To depict further potential of integration in this project we omitted the friction break of the rare axle. Due to legal regulations in Germany a breaking circuit on the rare axis has to be able for a deceleration of minimum $0.3 \mathrm{~g}$ [2]. This equates to a braking torque of ca. $670 \mathrm{Nm}$ per each motor. Therefore the machine has to carry high currents, independent from the thermal machine conditions. This maximum braking torque is required for just a very short time because such an emergency break lasts a few seconds only.

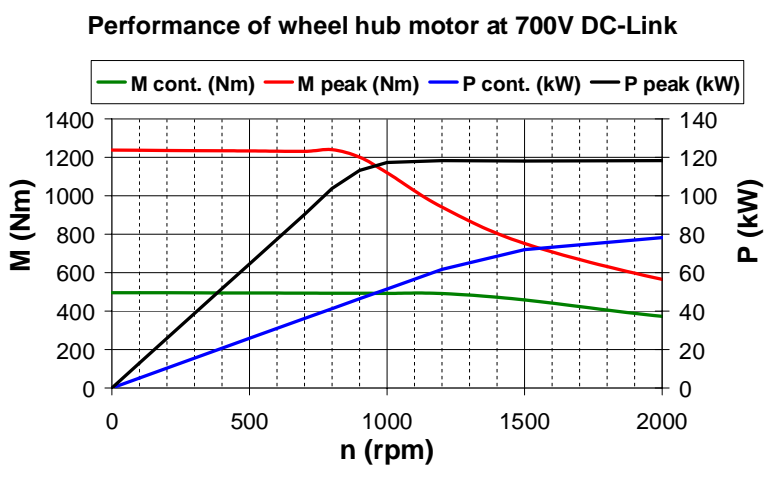

Figure 2: Torque-speed characteristic curve

Due to the application in respect of typical drive cycles for full electric vehicles (e.g. US06 rural, urban and highway) we designed the machine to a 
high efficiency to in part-load operational range. The efficiency map is shown in Figure 3. The machine has a maximum efficiency of $96.5 \%$ and shows $92.1 \%$ in the urban cycle, $94.5 \%$ in the rural cycle and $95.7 \%$ in the highway cycle.

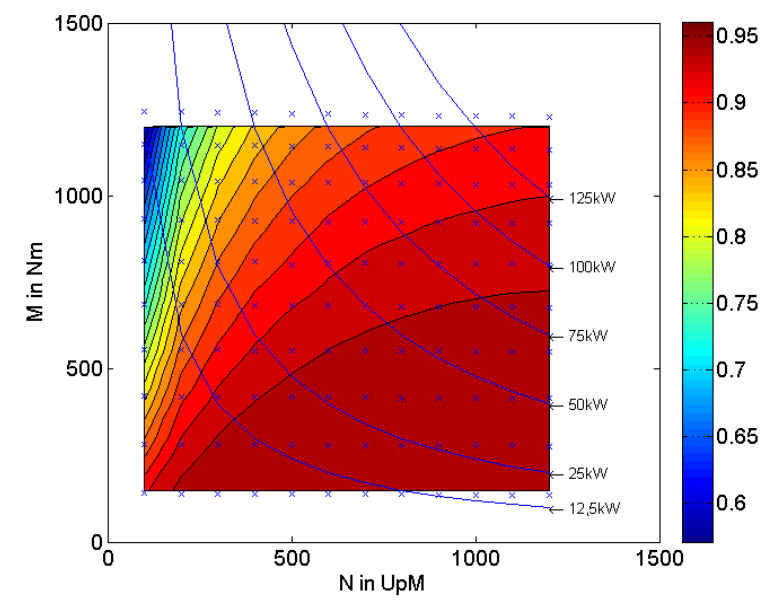

Figure 3: Efficiency map of wheel hub motor

A comparison with a common axle drive with central motor, gearbox, differential and drive shafts for a similar car application showed a difference in the overall drive train efficiency of $4 \%$ to $10 \%$, depending on the drive cycle.

\section{Vehicle integration}

We aimed from the first beginning to assemble two machines into a prototype vehicle. This way the behaviour of the whole system can be examined, first of all the interaction between wheel hub machine and friction brake. The car on a test rig is shown in Figure 4.

Our test carrier bases on a Roding Roadster. It holds a monocoque structure in the middle made of carbon fibre and glass fibre reinforced plastic. In the rear a self-supporting alumina frame is attached. The axle carriers are fixed to that frame. This vehicle is constructed as a batteryelectric vehicle. As mentioned above it features disc friction breaks on the front axle only. The speed of the rear axle is controlled just by the wheel hub motor. And this in both situations: acceleration and deceleration.

The regulations in Germany demand at least two independent break circuits [2]. In case of malfunction or breakdown of one circuit the redundant braking system has to be able to stop the car. Because of practical reasons two hydraulic circuits on the front axle are used. The wheel hub machines on the rare axle form the third braking circuit. It works independent of the hydraulic system. Here there is more potential savings on an electric drive train.

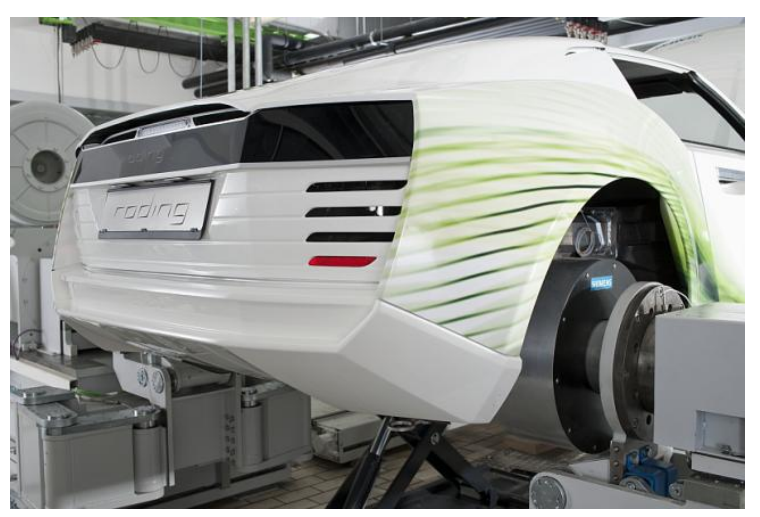

Figure 4: Test vehicle with 2 wheel hub drives

The first test drives showed the potential of such a vehicle. Due to the lack of shafts and gear boxes it climbs steps very smoothly because there is no torsion of shafts or bearing clearance in the differentials and gears. The high torque of the wheel hub machines, $2500 \mathrm{Nm}$ in sum, in combination with the low car weight of $1200 \mathrm{~kg}$ lead to an acceleration of less than 4,6s from $0 \ldots 100 \mathrm{~km} / \mathrm{h}$. Furthermore a comparatively high rate of electrical recuperation with a high efficiency is achievable. Test series on a test rig have been started to examine different recuperation and brake blending strategies.

Once in a while the additional unsprung masses of wheel hub drives are said to influence the driving behavior in a negative way. In our application the increase of the unsprung mass is less than $20 \mathrm{~kg}$ per wheel because of a weight optimization of the vehicle suspension and the loss of the mechanical braking system. Several publications [3], [4] expose that an increase of unsprung masses in that range don't effect noticeably the driving behavior during different typical drive cycles.

\section{Summary and outlook}

After we have developed different topologies of electric drive trains and examined them in prototype vehicles [5], we constructed a wheel hub motor. This is a consequent step in the electric drive train development, because this makes new car designs for car feasible. We combined the motor and the break in one piece of hardware. Our aim is to go on further this way. On the long range we will also integrate suspension, damping, electronics and steering into a wheel module. This will allow for cars that differ totally from what we know from the appearance today. 


\section{References}

[1] Mitchell, W.J.; Borroni-Bird, C. E.; Burns, L. D.: Reinventing the automobile: personal urban mobility for the 21st century; The MIT Press, Cambridge, MA, 2010

[2] Richtlinie 71/320/EWG (AB1. L 202 vom 6.9.1971)

[3] Syrnik, R: „Analyse der Auswirkung erhöhter ungefederter Radmassen auf das Fahrverhalten eines PKWs", Continental AG 2008

[4] Williams, S.: "Hub motor dynamics", Vehicle Dynamics International, Lotus engineering, 2011

[G] Freitag, G; Kuhn, K.-J.: "Hochintegrierter Antrieb: Radnabenantrieb ohne Reibbremse", in : "Trends in der elektrischen Antriebstechnologie für Hybrid- und Elektrofahrzeuge“, Frankfurt, 2011

\section{Authors}

Dr.-Ing. Marco Schramm was working as a postgraduate at the Chairs of Electric Machines and Drives in Chemnitz and Dresden. Since 2009 he is employed at Siemens, Corporate Technology in Erlangen, in the field of electromagnetic components and electric drives with an expertise in electric machine design. In 2010 he received a doctor's degree at the Dresden University of technology.

Dr.-Ing. Gunter Freitag was working at different positions at Eurocopter and Bosch Engineering GmbH. Since 2010 he is employed at Siemens, Corporate Technology in Munich. He works as a

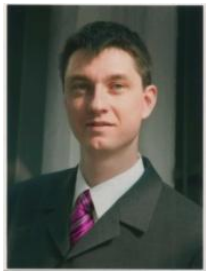
project leader in the subject of emobility mainly in the field of drive train components. He studied electrical engineering and economics. In 2005 he received a doctor's degree of engineering at Universität der Bundeswehr München in Munich. 